\title{
Ambulatory function in motor incomplete spinal cord injury: a magnetic resonance imaging study of spinal cord edema and lower extremity muscle morphometry
}

\author{
AC Smith ${ }^{1,2}$, KA Weber ${ }^{3}$, TB Parrish ${ }^{4}$, TG Hornby ${ }^{5}$, VM Tysseling ${ }^{2}$, JG McPherson ${ }^{6}$, M Wasielewski $^{2}$ \\ and JM Elliott ${ }^{2}$
}

\begin{abstract}
Study design: This research utilized a cross-sectional design.
Objectives: Spinal cord edema length has been measured with T2-weighted sagittal MRI to predict motor recovery following spinal cord injury. The purpose of our study was to establish the correlational value of axial spinal cord edema using T2-weighted MRI. We hypothesized a direct relationship between the size of damage on axial MRI and walking ability, motor function and distal muscle changes seen in motor incomplete spinal cord injury (iSCl).
\end{abstract}

Setting: University-based laboratory in Chicago, IL, USA.

Methods: Fourteen participants with iSCl took part in the study. Spinal cord axial damage ratios were assessed using axial T2-weighted MRI. Walking ability was investigated using the 6-min walk test and daily stride counts. Maximum plantarflexion torque was quantified using isometric dynomometry. Muscle fat infiltration (MFI) and relative muscle cross-sectional area ( $r m C S A)$ were quantified using fat/water separation magnetic resonance imaging.

Results: Damage ratios were negatively correlated with distance walked in $6 \mathrm{~min}$, average daily strides and maximum plantarflexion torque, and a negative linear trend was found between damage ratios and lower leg rmCSA. While damage ratios were not significantly correlated with MFI, we found significantly higher MFI in the wheelchair user participant group compared to community walkers.

Conclusions: Damage ratios may be useful in prognosis of motor recovery in spinal cord injury. The results warrant a large multi-site research study to investigate the value of high-resolution axial T2-weighted imaging to predict walking recovery following motor incomplete spinal cord injury.

Spinal Cord (2017) 55, 672-678; doi:10.1038/sc.2017.18; published online 28 February 2017

\section{INTRODUCTION}

Annually, an estimated 250 000-500 000 individuals suffer a spinal cord injury (SCI) worldwide. ${ }^{1}$ Incomplete spinal cord injury refers to a type of SCI where partial sensory and/or motor function is, to some degree, preserved below the level of the injury. ${ }^{2}$ Generally, patients with motor incomplete spinal cord injury (iSCI) are expected to recover at least some walking ability ${ }^{3}$ but not without deficits in generating maximal volitional torque. ${ }^{4}$ The size and volitional activation of the lower extremity musculature is likely to factor ${ }^{4,5}$ in maximizing ambulatory recovery, which remains a top priority in rehabilitative programs. ${ }^{6}$ An expected adaptation of motor incomplete spinal cord injury is change in muscle structure distal to the level of injury ${ }^{7,8}$ (for example, decreased muscle cross-sectional area (atrophy), and muscle fat infiltration (MFI)). ${ }^{9-11}$ While atrophy and MFI of lower extremity musculature can be quantified using magnetic resonance imaging (MRI), ${ }^{5,12}$ their directional relationship to the damaged area of the cervical cord and ambulatory status are largely unknown.

Predicting neurologic functional recovery in cervical spinal cord injury with postoperative MRI has been widely utilized. ${ }^{13-22} \mathrm{~A}$ number of studies have demonstrated that edema without hemorrhage in the cervical cord suggests a more favorable functional outcome with iSCI. ${ }^{14,15,17}$ Further work has measured and related the length of edema to motor abilities and prognosis. ${ }^{13-15,23,24}$ However, due to insufficient T2 contrast in the damaged cord, questions remain regarding the prognostic value of such an approach. ${ }^{25}$

With technological advancements in today's and tomorrow's MRI sequences, the quantification of spinal cord edema and its predictive relationship to muscle health and motor function (for example, walking ability ${ }^{26}$ decreased lower extremity maximum torque output, ${ }^{4}$ decreased muscle cross-sectional area (atrophy) distal to the injury site, ${ }^{12}$ and muscle fat infiltration ${ }^{9-11}$ ) may be realized. The purpose of this cross-sectional study was to use high-resolution axial T2-weighted MRI to quantify spinal cord edema in participants with iSCI, and to relate this metric of cord damage to walking ability (6-min walk test and daily stride count), lower extremity torque production, lower extremity muscle CSA, and MFI. We hypothesized that spinal cord edema would be negatively correlated with walking ability, torque production, and muscle CSA, but positively

${ }^{1}$ Regis University School of Physical Therapy, Denver, CO, USA; ${ }^{2}$ Northwestern University Department of Physical Therapy and Human Movement Sciences, Chicago, IL, USA; ${ }^{3}$ Stanford University Department of Anesthesia, Perioperative and Pain Medicine, Palo Alto, CA, USA; ${ }^{4}$ Northwestern University Department of Radiology, Chicago, IL, USA;

${ }^{5}$ Rehabilitation Institute of Chicago, Chicago, IL, USA and ${ }^{6}$ Florida International University Department of Biomedical Engineering, Miami, FL, USA

Correspondence: Dr AC Smith, Regis University School of Physical Therapy, 3333 Regis Boulevard, Peter Claver Hall office 423D, C0, Denver 80221, USA

E-mail: asmith034@regis.edu

Received 3 June 2016; revised 25 January 2017; accepted 28 January 2017; published online 28 February 2017 
Table 1 Participant characteristics

\begin{tabular}{|c|c|c|c|c|c|c|c|c|c|c|}
\hline Participant \# & Gender & Age (years) & Height $(\mathrm{cm})$ & Weight (kg) & $\begin{array}{c}\text { BMI } \\
\text { (units) }\end{array}$ & $\begin{array}{c}\text { Time since injury } \\
\text { (years) }\end{array}$ & $\begin{array}{l}\text { Mechanism of } \\
\text { injury }\end{array}$ & $\begin{array}{l}\text { Level of } \\
\text { injury }\end{array}$ & $\begin{array}{l}\text { ASIA impairment } \\
\text { Scale }\end{array}$ & $\begin{array}{l}\text { Primary } \\
\text { ambulation }\end{array}$ \\
\hline iSCl1 & M & 53 & 185 & 82.1 & 23.9 & 6 & MVC & $\mathrm{C} 5$ & $\mathrm{C}$ & Wheelchair \\
\hline iSCl2 & M & 57 & 178 & 79.4 & 25.1 & 8 & Cycling Injury & C3 & $\mathrm{D}$ & Walk with $A D$ \\
\hline iSCl3 & $\mathrm{F}$ & 52 & 157 & 83.9 & 33.8 & 0.5 & MVC & $\mathrm{C} 6$ & $\mathrm{D}$ & Walk with $A D$ \\
\hline iSCl4 & M & 31 & 178 & 72.6 & 23.0 & 4 & Diving Injury & C5 & $\mathrm{D}$ & Walk with $A D$ \\
\hline iSCI5 & M & 28 & 188 & 95.3 & 27.0 & 3 & Diving Injury & C5 & $\mathrm{D}$ & Walk \\
\hline isCl6 & $M$ & 50 & 168 & 83.9 & 29.9 & 2 & Fall from Height & $\mathrm{C} 6$ & D & Walk \\
\hline iSCI7 & M & 30 & 193 & 115.7 & 31.0 & 4 & Diving Injury & C6 & C & Wheelchair \\
\hline iscl8 & M & 27 & 191 & 86.2 & 23.7 & 4 & Skiing Injury & C5 & C & Wheelchair \\
\hline iscl9 & M & 32 & 173 & 81.7 & 27.4 & 5 & MVC & $\mathrm{C7}$ & D & Walk \\
\hline iSCI10 & $M$ & 45 & 175 & 59.0 & 19.2 & 4 & ATV Injury & C3 & $\mathrm{D}$ & Walk with $A D$ \\
\hline iSCI11 & M & 36 & 185 & 73.5 & 21.4 & 2 & Motorcycle Injury & $\mathrm{C} 6$ & C & Wheelchair \\
\hline iSCI12 & M & 50 & 178 & 72.6 & 23.0 & 5 & Fall from Height & $\mathrm{C} 4$ & $\mathrm{D}$ & Wheelchair \\
\hline iSCI13 & M & 64 & 175 & 108.9 & 35.5 & 4 & Fall & $\mathrm{C} 5$ & D & Wheelchair \\
\hline iSCI14 & M & 52 & 175 & 70.3 & 22.9 & 31 & Diving injury & $\mathrm{C} 5$ & $D$ & Wheelchair \\
\hline
\end{tabular}

Abbreviations: AD, assistive device; ATV, all terrain vehicle; BMI, body mass index; MVC, motor vehicle collision.

correlated with the lower extremity MFI. For a secondary analysis, we hypothesized wheelchair ambulators to have higher MFI and lower muscle CSA compared to those not requiring a wheelchair.

\section{MATERIALS AND METHODS}

\section{Participant characteristics}

Participants were recruited from the Rehabilitation Institute of Chicago's Spinal Cord Injury database, in accordance with Northwestern University IRB \#STU00087983 and the Declaration of Helsinki. Fourteen individuals with chronic cervical iSCI participated ( 1 female and 13 males, average age $=43 \pm 12$ years old). Four individuals with iSCI were classified using the American Spinal Cord Injury Association Impairment Scale (AIS) as AIS C C5-8 level, 2 participants were classified as AIS D C1-4 level, and 8 participants were classified as AIS D C5-8 level. Seven participants used walking as their primary mode of community ambulation, while seven used wheelchairs for community ambulation. See Table 1 for details on the participant characteristics, including time since injury.

We certify that all applicable institutional and governmental regulations concerning the ethical use of human volunteers were followed during the course of this research.

\section{MAGNETIC RESONANCE IMAGING}

\section{Spinal cord imaging}

T2-weighted imaging of the cervical spinal cord was performed using a 3.0 Tesla Prisma magnetic resonance (MR) scanner equipped with a 64-channel head/neck coil (Siemens, Erlangen, Germany). A high-resolution T2-weighted structural image of the cervical spine and spinal cord damage site was acquired using a 2D turbo spin echo sequence, and 16 slices were oriented to be perpendicular to the spinal cord edema $\quad(F O V=260 \mathrm{~mm}$ square field of view, $\mathrm{TR}=2380 \mathrm{~ms}, \mathrm{TE}=102 \mathrm{~ms}$, flip angle $=120^{\circ}$, number of averages $=3$, bandwidth $=651 \mathrm{~Hz} / \mathrm{Px}$, phase encoding direct: right to left, resolution $=0.5 \times 0.5 \times 2.0 \mathrm{~mm}^{3}$, acquisition matrix $\left.=512 \times 282\right)$. The acquisition time was 6:30 min. Spinal cord MRI data were analyzed offline using OsiriX image processing software (Pixmeo, Geneva, Switzerland). The OsiriX interpolation function was used for clearer visualization of edema. For each participant, using the slice where the spinal cord edema of maximum area was measured, the crosssectional area of edema was obtained, and a damage ratio was calculated as maximum spinal cord edema CSA divided by the CSA of the surrounding spinal cord. A value of zero suggests no edema, where a value of one equates to the edema covering the full region of the spinal cord (Figure 1).

\section{6-min walk test}

Each participant completed an over ground 6-min walk test, where the total distance walked within a 6-min time frame was measured. ${ }^{27}$ Participants were instructed to walk at their normal, self-selected pace, and were allowed to use assistive devices and braces as necessary. The 6-min walk test has been shown to be reliable and valid in iSCI. ${ }^{27,28}$

\section{Daily stepping}

Each participant wore an ankle step monitor with an accelerometer for a 2-week window, in order to quantify average daily strides. ${ }^{29}$ Participants were instructed to wear the step monitor at all times except when bathing/showering. Previous literature verified that a $\geqslant 3$-day window of acquiring step data is sufficient for a reliable estimate of stepping activity. ${ }^{30}$

Walking index for spinal cord injury. A licensed physical therapist rated each participant on a locomotor scale, the Walking Index for Spinal Cord Injury II. This scale ranks the ability of the participant to walk 10 meters, and has been demonstrated to have excellent inter-rater reliability and to be a valid tool in SCI. ${ }^{31}$

\section{Isometric plantarflexion torque}

For isometric ankle plantarflexion torque measurement, participants were secured in a seated position with both ankles at neutral, knees flexed at $20^{\circ}$, and hips flexed to $75^{\circ}$. Maximum volitional torque (MVT) was established following three maximal isometric contractions of the plantarflexors, each contraction held 3-4s duration in an isokinetic dynamometer, with each leg tested separately (Biodex Rehabilitation System v3, Shirley, NY, USA). Verbal encouragement to facilitate maximum torque production was provided. ${ }^{32}$ Torque traces were monitored during each trial on a biofeedback screen.

\section{Muscle fat infiltration and lower extremity muscle CSA}

For both the leg muscle cross-sectional area and muscle fat infiltration quantification, a chemical shift based, 3D dual-echo gradient, Dixon method fat-water separation MRI technique was performed on all participants. ${ }^{33,34}$ The 2-point Dixon examination included the major muscle groups of the lower leg: gastrocnemius, soleus, tibialis 


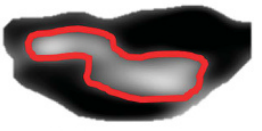

isCl1: 0.29

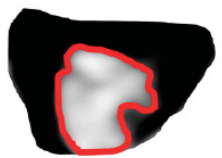

isCl5: 0.32

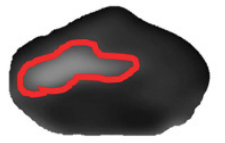

isC19: 0.17

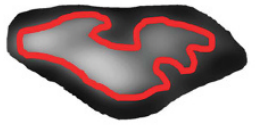

isCl13: 0.43

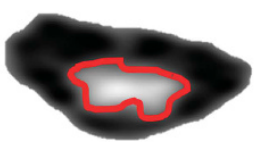

isCl2: 0.20

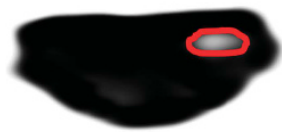

isCl6: 0.10

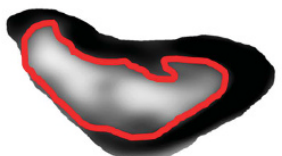

isCl10: 0.49

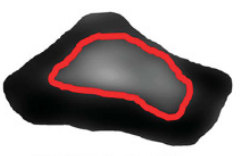

isCI14: 0.34

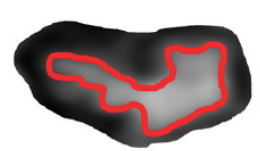

isCl3: 0.39

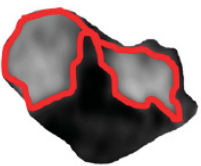

iSCl7: 0.47

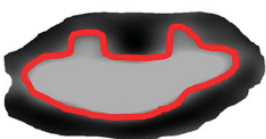

isCl1 1: 0.39

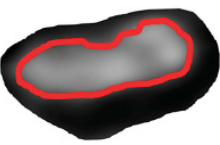

isCl4: 0.35

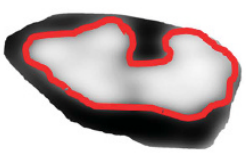

isCl8: 0.57

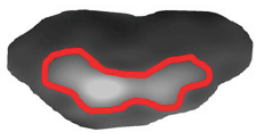

isCl12: 0.32

Figure 1 Axial T2-weighted images of spinal cord edema in each participant with iSCl, with corresponding damage ratios listed. Damage ratios were calculated as edema area divided by the surrounding spinal cord area.

anterior, and peroneous longus. The specific Dixon MRI parameters for the lower extremities included: $T R=6.59 \mathrm{~ms}$, TE1 $=2.45 \mathrm{~ms}$ TE2 $=3.675 \mathrm{~ms}$, flip angle $=12$ degrees, bandwidth $1=510$ bandwidth $2=660 \mathrm{~Hz} / \mathrm{Px}$ and an imaging matrix of $448 \times 266$. A read field of view of $320-340 \mathrm{~mm}$ was used on the lower extremity muscles using a 16-channel body array surface coil, and 60 slices per slab with a slice thickness of $5 \mathrm{~mm}$ and a slice oversampling of $6.7 \%$ were acquired. The acquisition time was $4: 12 \mathrm{~min}$ with a rectangular view of $60 \%$, four averages and an in-plane resolution of $0.5 \mathrm{~mm}$. Localizer scans were used to obtain the fat/water data in the axial plane perpendicular to the tibia.

Analysis of the lower extremity MRI data was performed using customized imaging analysis scripts created in MatLab (Version 2014b, MathWorks, Natick, MA, USA). One experienced researcher manually defined each region of interest (ROI) in the four leg muscle groups by contouring each muscle within its fascial borders with the co-registered fat- and water-saturated sequences. The MFI percentage is a value of fat signal intensity to fat-plus-water signal intensity, and these MFI percentages were created using the equation:

$[$ Relative fat signal $/($ relative water + relative fat signal $)] \times 100$

Sixty slices were obtained through the leg, and averages were taken over 10 consecutive slices throughout the muscle bulk of each of the four lower extremity muscles to form individual MFI percentages. ${ }^{34}$

Each outline of the 4 individual lower extremity muscles yielded a CSA value. Average individual muscle CSA values were taken across 10 consecutive slices of muscle bulk, total CSA values were taken as a sum of all 4 muscles, and the relative muscle CSA (rmCSA) was calculated by removing the fat infiltration ${ }^{35}$, using the equation:

$$
\mathrm{rmCSA}=\mathrm{CSA} \times(1-\mathrm{MFI}) .
$$

\section{Statistical analysis}

All statistical analyses of the data were performed using IBM SPSS (Version 21, Armonk, NY, USA). All data were tested for normality using Kolmogorov-Smirnov statistical analyses. Intra-class correlation coefficients (ICC 2,1) were used to test the inter- and intra-rater reliability of the spinal cord damage ratio measure. Rater one took measurements two months apart for intra-rater testing, and rater two took a separate measure of damage ratios to establish inter-rater reliability. Pearson correlations were employed to examine linear relationships between spinal cord damage ratios and distance walked in $6 \mathrm{~min}$, average daily strides, plantarflexion torque production, relative muscle CSA, and MFI. A 2-way ANOVA was utilized to test for significant MFI differences between wheelchair user and community walker participant groups, as well as between the four muscle groups, with Bonferroni post hoc correction. An independent samples $t$-test was used to test for a significant difference in total lower leg rmCSA between the wheelchair user and community walker participant groups. $P$-values of $<0.05$ were considered significant.

\section{RESULTS}

All of the data met assumptions of normality using Kolmogorov-Smirnov statistical analyses. Individual data are presented in Tables 2 and 3.

\section{Spinal cord imaging}

The damage ratio measurement showed high inter-rater (ICC 2, 1=0.82) and high intra-rater reliability (ICC 2, 1=0.92). Damage ratios were negatively correlated with distance walked in $6 \mathrm{~min}(R=-0.72, \quad P<0.01$, Figure $2 \mathrm{a})$, average daily strides $(R=-0.74, P<0.01$, Figure $2 \mathrm{~b})$, and isometric plantarflexion MVT ( $R=-0.61, P=0.02$, Figure $2 \mathrm{c}$ ). Damage ratios were also negatively correlated with the Walking Index for Spinal Cord Injury II scores (Spearman's rho $=-0.70, P<0.01$ ). A non-significant negative linear trend was found between damage ratios and lower leg rmCSA ( $R=-0.50, P=0.06)$. Damage ratios were not significantly correlated with MFI $(R=0.30, P=0.31)$.

\section{Isometric plantarflexion torque}

Isometric plantarflexion MVT was significantly positively correlated with plantarflexor rmCSA $(R=0.53, P<0.01)$. This relationship held when the weaker sided MVT was correlated with the weaker plantarflexor rmCSA $(R=0.55, P=0.04)$ and when the stronger sided 
Table 2 Individual participant data—damage ratios, walking and plantarflexion torque

\begin{tabular}{|c|c|c|c|c|c|c|}
\hline Participant \# & Primary ambulation & Damage ratio & $6 M W$ distance $(m)$ & Average daily strides & Right plantarflexion MVT (Nm) & Left plantarflexion MVT (Nm) \\
\hline iSCl1 & Wheelchair & 0.29 & 64 & 247 & 30.03 & 45.52 \\
\hline iSCl2 & Walk with $A D$ & 0.20 & 187 & 2036 & 64.45 & 82.93 \\
\hline iscl3 & Walk with $A D$ & 0.39 & 147 & 1166 & 93.00 & 86.00 \\
\hline iSCl4 & Walk with $A D$ & 0.35 & 134 & 1557 & 29.56 & 44.35 \\
\hline isCl5 & Walk & 0.32 & 409 & 1483 & 72.98 & 149.05 \\
\hline iscl6 & Walk & 0.10 & 412 & 2786 & 133.29 & 104.91 \\
\hline iSCI7 & Wheelchair & 0.47 & 49 & 372 & 12.69 & 52.80 \\
\hline iscl8 & Wheelchair & 0.57 & 30 & 330 & 29.73 & 12.66 \\
\hline iscI9 & Walk & 0.17 & 431 & 3077 & 61.26 & 83.56 \\
\hline iSCI10 & Walk with $A D$ & 0.49 & 165 & 1108 & 55.46 & 68.29 \\
\hline iSCI11 & Wheelchair & 0.39 & 98 & 745 & 36.13 & 80.84 \\
\hline iSCI12 & Wheelchair & 0.32 & 244 & 879 & 95.61 & 92.40 \\
\hline iSCl13 & Wheelchair & 0.43 & 166 & 1681 & 57.85 & 49.25 \\
\hline iSCl14 & Wheelchair & 0.34 & 241 & 2035 & 47.59 & 37.70 \\
\hline
\end{tabular}

Abbreviations: MVT, maximum voluntary torque; $6 \mathrm{MW}, 6$ min walk test.

Table 3 Individual participant data-leg muscle measures

\begin{tabular}{|c|c|c|c|c|c|c|c|}
\hline Participant \# & $\begin{array}{l}\text { Primary } \\
\text { ambulation }\end{array}$ & $\begin{array}{c}\text { Weaker leg MFI } \\
\text { sverage } \%\end{array}$ & $\begin{array}{c}\text { Stronger leg MFI } \\
\text { sverage } \%\end{array}$ & $\begin{array}{c}\text { Weaker leg } \\
\text { rmCSA }\left(\mathrm{mm}^{2}\right)\end{array}$ & $\begin{array}{l}\text { Stronger leg } \\
\operatorname{rmCSA}\left(\mathrm{mm}^{2}\right)\end{array}$ & $\begin{array}{c}\text { Weaker plantarflexor } \\
\text { rmCSA }\left(\mathrm{mm}^{2}\right)\end{array}$ & $\begin{array}{c}\text { Stronger plantarflexor } \\
r m C S A\left(m^{2}\right)\end{array}$ \\
\hline iSCI1 & Wheelchair & 15.77 & 20.49 & 3419.24 & 3316.51 & 2427.90 & 2374.22 \\
\hline isCl2 & Walk with $A D$ & 10.55 & 10.18 & 5474.11 & 5645.74 & 3777.80 & 4530.76 \\
\hline iSCI3 & Walk with $A D$ & 16.40 & 18.59 & 3638.03 & 3479.53 & 2796.45 & 2646.78 \\
\hline iSCl4 & Walk with $A D$ & 14.76 & 13.50 & 3416.86 & 3740.00 & 2135.72 & 2631.87 \\
\hline iSCl5 & Walk & 18.17 & 11.49 & 4199.98 & 5798.23 & 2766.60 & 4377.08 \\
\hline isCl6 & Walk & 17.12 & 15.77 & 4967.27 & 5167.29 & 3638.70 & 3856.84 \\
\hline iSCI7 & Wheelchair & 14.85 & 14.56 & 4547.62 & 5437.89 & 3488.80 & 4328.72 \\
\hline iSCI8 & Wheelchair & 15.59 & 15.17 & 3493.28 & 3595.58 & 2298.98 & 2480.93 \\
\hline isCI9 & Walk & 8.27 & 7.38 & 4312.88 & 4260.17 & 3127.48 & 3136.14 \\
\hline iSCI10 & Walk with $A D$ & 9.44 & 14.66 & 4095.98 & 2848.33 & 3035.90 & 2217.98 \\
\hline iSCI11 & Wheelchair & 15.05 & 15.68 & 3015.63 & 2858.92 & 2244.92 & 2099.31 \\
\hline isCl12 & Wheelchair & 19.57 & 21.47 & 4860.93 & 4437.77 & 3673.20 & 3266.37 \\
\hline isCl13 & Wheelchair & 41.23 & 26.98 & 3751.46 & 3837.91 & 2740.81 & 2443.50 \\
\hline isCl14 & Wheelchair & 20.08 & 19.09 & 4037.51 & 3725.69 & 3077.57 & 2692.69 \\
\hline
\end{tabular}

Abbreviations: MFI, muscle fat infiltration; rmCSA, relative muscle cross-sectional area; $6 \mathrm{MW}, 6$ min walk test.

MVT was correlated with the stronger sided plantarflexor rmCSA $(R=0.54, P=0.04)$.

\section{Muscle fat infiltration and lower extremity muscle CSA}

The wheelchair user participant group had significantly elevated lower extremity MFI compared to the community walker group $(\mathrm{F}=17.62$, $\mathrm{df}=1, P<0.01$, mean difference $=6.38$, Figure $3 \mathrm{c}$ ). The peroneous longus had higher MFI compared to the tibialis anterior $(F=3.91$, $\mathrm{df}=3$, mean difference $=6.93, P=0.01$ ), otherwise there were no significant differences between the other muscle groups. There were no significant interaction effects. There were no significant differences in leg rmCSA between groups (mean difference $=958 \mathrm{~mm}^{2}, P=0.28$ ).

\section{DISCUSSION}

This study demonstrated a negative correlation between damaged cord ratios and both walking ability and plantarflexion torque output in participants with iSCI. These findings suggest that axial spinal cord damage ratios on high-resolution T2-weighted MRI may be useful in predicting recovery of walking ability early after spinal cord injury. However, important questions must be addressed. How soon following injury can the extent of the spinal cord edema be used in such a predictive model? Evidence from canine and murine weight-drop contusion models of SCI found a 2-week time point for the initial formation of a fluid-filled cavity and a 4-week time point for completed edema formation. ${ }^{36}$ Human work into SCI found that spinal cord edema was visualized using sagittal T2-weighted MRI within approximately $3-4$ days post injury. ${ }^{17}$

Previous literature evinced the length of the spinal cord edema on T2-weighted MRI was related to neurological status tested using ASIA and Frankel classifications. ${ }^{13,37,38}$ One study showed that edema length was negatively linearly correlated with the Functional Independence Measure (FIM) locomotor score $(R=-0.22)$ and with the FIM motor scale $(R=-0.36)$ upon discharge. ${ }^{23}$ Using advanced but available spinal cord fiber tractography (FT), a positive correlation was reported between FT parameters and upper extremity motor scores post SCI (Spearman's rho range $=0.648-0.794) .{ }^{39}$ For a secondary analysis of our data, focusing on our clinical measures, we found that damage ratios were significantly negatively correlated with FIM locomotor scores (Spearman's rho $=-0.62, P=0.02$ ), ASIA lower extremity motor scores (Spearman's rho $=-0.72, P<0.01$ ), and the Walking 
Index for Spinal Cord Injury II (Spearman's rho $=-0.70, P<0.01$ ). See Table 4 for individual clinical measures.

Additionally, we observed a negative linear trend between damage ratios and leg rmCSA, and found that rmCSA was significantly correlated with ability to generate plantarflexion torque. These findings are in accordance with previous research reporting decreased lower extremity $\mathrm{CSA}^{5}$ and decreased torque production in iSCI. ${ }^{4}$

One surprising finding was that damage ratios were not significantly correlated with lower extremity MFI. Though denervation is one established cause of increased MFI, ${ }^{40-42}$ other factors such as physical in-activity, ${ }^{43}$ altered metabolic function, ${ }^{44}$ and overall weight gain ${ }^{45}$ certainly play a role. One theory is that while the spinal cord injury may dictate overall motor function, the amount of muscle fat infiltration may be more related to the post-injury physical activity levels on a patient-by-patient basis. Indeed, when our participants were subgrouped into wheelchair users versus community walkers, a significant lower extremity MFI difference was found. This finding is in-line with previous research where patients with iSCI had significantly higher lower extremity MFI than able-bodied matched controls. ${ }^{10}$

\section{Future direction}

Using qualitative MRI parameters (that is, presence/absence of edema) along with clinical metrics, researchers used a multiple regression model to create a clinical prediction rule for determining long-term functional outcome following spinal cord injury, ${ }^{19}$ reporting an $R^{2}$ value of 0.52 . We believe that our quantitative damage ratio metric may be valuable for a clinical prediction rule of future walking ability. Damage ratios alone yielded an $R^{2}$ value of 0.52 when correlating with distance walked in $6 \mathrm{~min}$. After selecting the three most robust variables from our data set, we created a multiple regression equation using damage ratios, ASIA lower extremity motor scores (LEMS), and average plantarflexion MVT to predict average daily strides.

Multiple Regression Equation:

$$
\begin{aligned}
\text { Average daily strides }= & -1547(\text { damage ratio }) \\
& +90(\text { ASIA LEMS })-9(\mathrm{MVT})-858, R^{2} \\
= & 0.77, \mathrm{~F}=10.94, P<0.01 .
\end{aligned}
$$

With an $R^{2}$ of 0.77 , this type of multiple regression analysis using quantitative MRI parameters may be useful for predicting walking ability following spinal cord injury. While we acknowledge that these data were measured in the chronic state, we believe these strong relationships warrant longitudinal investigation.

\section{Limitations}

An inherent limitation of this cross-sectional study remains our inability to provide a cause-and-effect relationship between the
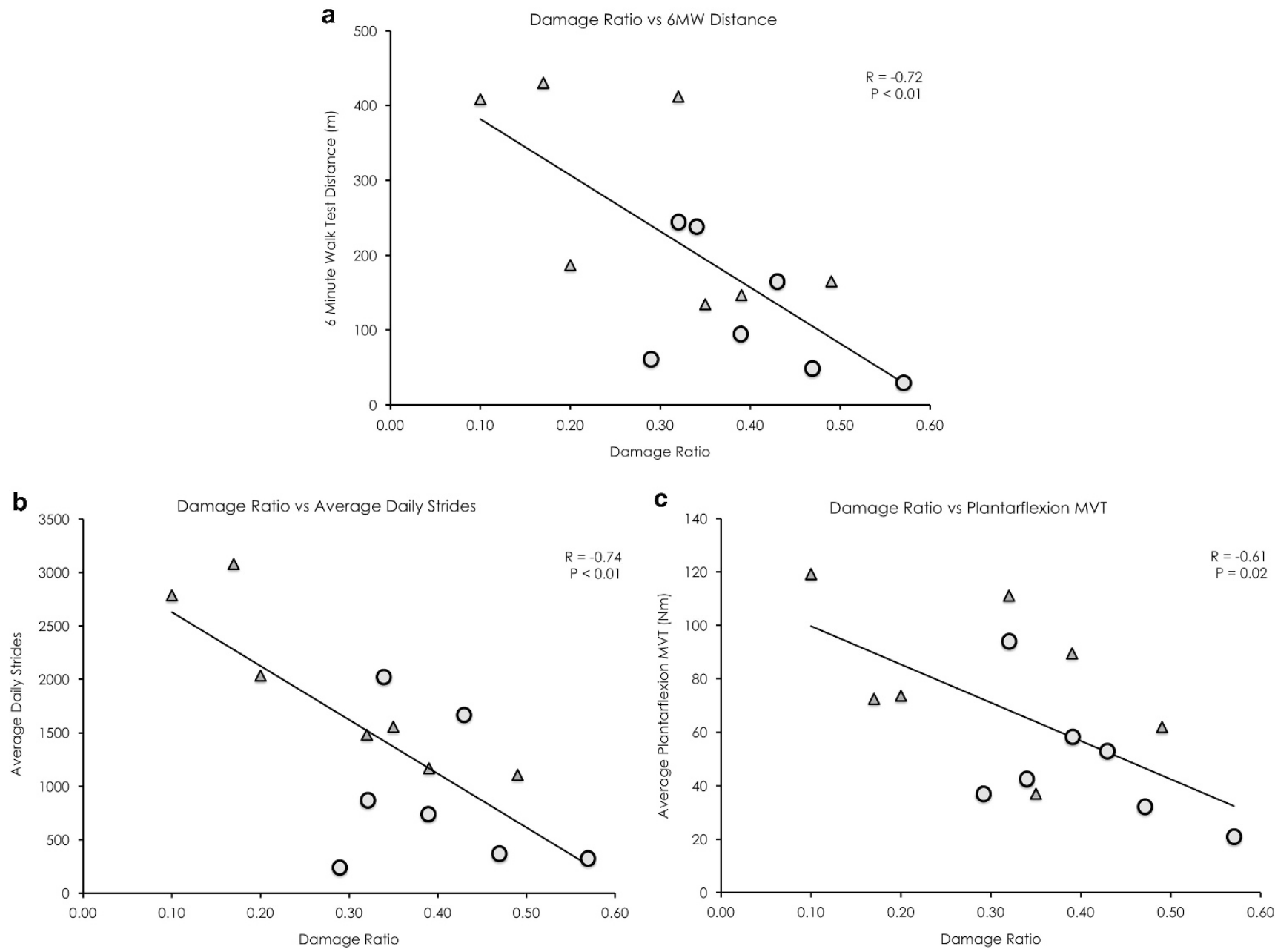

Figure 2 Damage ratios versus meters walked in 6 min (a), average daily strides (b), and isometric plantarflexion maximum voluntary torque (c). Significant negative linear correlations were found $(R=-0.72, P<0.01 ; R=-0.74, P<0.01 ; R=-0.61, P=0.02$; respectively). Wheelchair user participants are identified as circular data points, while community ambulator participants are identified as triangular data points. 


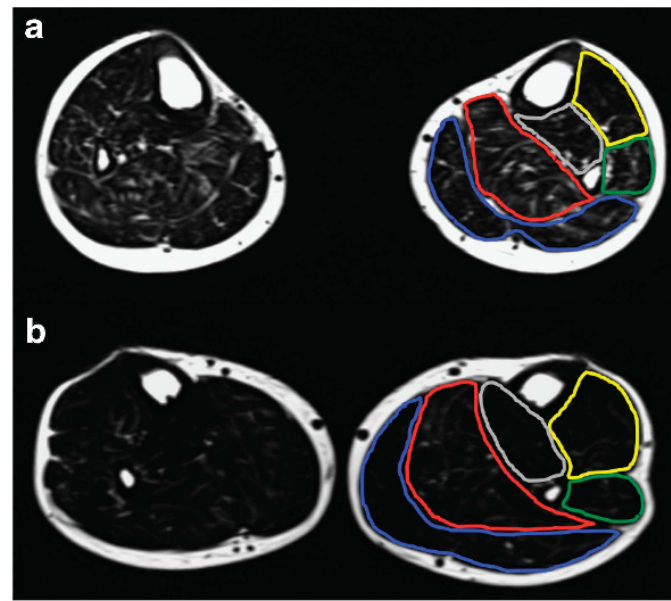

C Average Lower Extremity Muscle Fat Infiltration

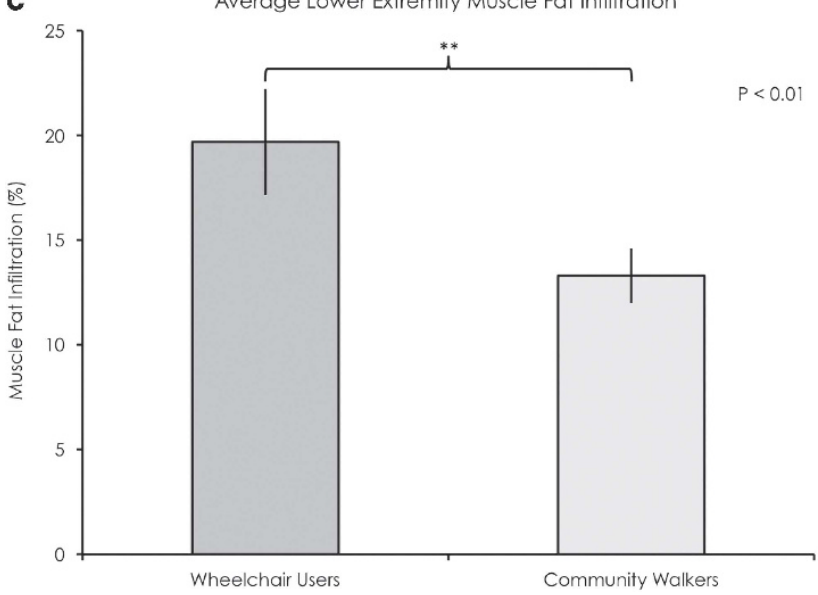

Figure 3 Cross-sectional fat-saturated images of the leg muscles in a representative wheelchair user participant (a) and a representative community walker participant (b). Outlines delineate major leg muscle groups (blue: gastrocnemius, red: soleus, yellow: tibialis anterior, green: peroneus longus). (c) A significant difference in $\mathrm{MFI}$ was found between groups $(P<0.01)$. Error bars denote s.e. of mean. amount of spinal cord damage and ambulatory ability. However, once the optimal time-course for axial T2 imaging of spinal cord edema is established, the prognostic value of the cord edema ratio measure towards predicting ambulatory recovery should be further explored.

\section{CONCLUSION}

In this study, we demonstrated that measurement of spinal cord edema using high-resolution axial T2-weighted imaging is possible and that damage ratios were negatively correlated with ambulatory status as well as plantarflexion torque generation in 14 participants with iSCI. The seven community walkers had significantly lower MFI in their lower extremities compared to the seven using a wheelchair. A large multi-site investigation is warranted to examine the value of highresolution axial $\mathrm{T} 2$-weighted imaging to predict walking recovery following motor incomplete spinal cord injury.

\section{DATA ARCHIVING}

There were no data to deposit.

\section{CONFLICT OF INTEREST}

Elliott JM and Parrish TB-Relevant financial activities outside the submitted work: board membership, consultancy, other (Pain ID LLC), payment for lectures. The remaining authors declare no conflict of interest.

\section{ACKNOWLEDGEMENTS}

We thank all participants for their willingness to take part in this study. We thank Mark A Hoggarth for his assistance with the MatLab programming used to analyze the MFI data, and we thank Gordhan Mahtani and Mark Connolly for their assistance with participant recruitment and data collection. JME is supported by the NIH award 1 R01HD079076-01A1, entitled 'Neuromuscular Mechanisms Underlying Poor Recovery from Whiplash Injuries'. ACS is supported by the NIH Extramural Loan Repayment Program for Clinical Researchers funded by the National Institute of Neurological Disorders and Stroke, and by the Foundation for Physical Therapy Promotion of Doctoral Studies programs. KAW is supported by the Interdisciplinary Research Training in Pain and Substance Use Disorders T32DA035165 funded by the National Institute on Drug Abuse. This research was conceptualized and carried out at Northwestern University

Table 4 Individual participant data-FIM locomotor, ASIA LEMS and WISCI II scores

\begin{tabular}{|c|c|c|c|c|c|c|}
\hline Participant \# & Primary ambulation & Damage ratio & FIM locomotor (out of 7) & WISCI II (out of 20) & ASIA LEMS left (out of 25) & ASIA LEMS right (out of 25) \\
\hline iSCl1 & Wheelchair & 0.29 & 5 & 13 & 15 & 14 \\
\hline iSCl2 & Walk with $A D$ & 0.20 & 6 & 16 & 24 & 19 \\
\hline iSCl3 & Walk with $A D$ & 0.39 & 6 & 15 & 19 & 23 \\
\hline iSCl4 & Walk with $A D$ & 0.35 & 6 & 19 & 24 & 14 \\
\hline iSCl5 & Walk & 0.32 & 7 & 20 & 25 & 20 \\
\hline iscl6 & Walk & 0.10 & 7 & 20 & 23 & 25 \\
\hline iSCI7 & Wheelchair & 0.47 & 2 & 6 & 19 & 8 \\
\hline iscl8 & Wheelchair & 0.57 & 1 & 6 & 8 & 10 \\
\hline iscl9 & Walk & 0.17 & 7 & 20 & 25 & 22 \\
\hline iscl10 & Walk with $A D$ & 0.49 & 6 & 16 & 16 & 14 \\
\hline iSCI11 & Wheelchair & 0.39 & 6 & 9 & 23 & 10 \\
\hline iSCI12 & Wheelchair & 0.32 & 6 & 19 & 23 & 15 \\
\hline iSCI13 & Wheelchair & 0.43 & 6 & 13 & 19 & 22 \\
\hline iscl14 & Wheelchair & 0.34 & 6 & 15 & 17 & 24 \\
\hline
\end{tabular}

Abbreviations: ASIA LEMS, American Spinal Cord Injury Association Lower Extremity Motor Scores; FIM, functional independence measure; WISCI, walking index for spinal cord injury. 
1 Singh A, Tetreault L, Kalsi-Ryan S, Nouri A, Fehlings MG. Global prevalence and incidence of traumatic spinal cord injury. Clin Epidemiol 2014; 6: 309-331.

2 Jackson A, Dijkers M, Devivo M, Poczatek R. A demographic profile of new traumatic spinal cord injuries: change and stability over 30 years. Arch Phys Med Rehabil 2004; 85: $1740-1748$.

3 McKinley WO, Seel RT, Hardman JT. Nontraumatic spinal cord injury: incidence, epidemiology, and functional outcome. Arch Phys Med Rehabil 1999; 80: 619-623.

4 Jayaraman A, Gregory C, Bowden M, Stevens J, Shah P, Behrman A. Lower extremity skeletal muscle function in persons with incomplete spinal cord injury. Spinal Cord 2006; 44: 680-687.

5 Shah P, Stevens J, Gregory CM, Pathare NC, Jayaraman A, Bickel SC et al. Lower-extremity muscle cross-sectional area after incomplete spinal cord injury. Arch Phys Med Rehabil 2006; 87: 772-778.

6 Ditunno PL, Patrick M, Stineman M, Ditunno JF. Who wants to walk? Preferences for recovery after SCl: a longitudinal and cross-sectional study. Spinal Cord 2008; 46: 500-506.

7 Giangregorio L, McCartney N. Bone loss and muscle atrophy in spinal cord injury: epidemiology, fracture prediction, and rehabilitation strategies. J Spinal Cord Med 2006; 29: 489-500.

8 Biering-Sørensen B, Kristensen IB, Kjaer M, Biering-Sørensen F. Muscle after spinal cord injury. Muscle Nerve 2009; 40: 499-519.

9 Moore C, Craven B, Thabane L, Laing AC, Frank-Wilson AW, Kontulainen SA et al. Lower-extremity muscle atrophy and fat infiltration after chronic spinal cord injury. J Musculoskelet Neuronal Interact 2015; 15: 32-41.

10 Gorgey AS, Dudley GA. Skeletal muscle atrophy and increased intramuscular fat after incomplete spinal cord injury. Spinal Cord 2007; 45: 304-309.

11 Elder C, Apple D, Bickel C, Meyer R, Dudley G. Intramuscular fat and glucose tolerance after spinal cord injury-a cross-sectional study. Spinal Cord 2004; 42: 711-716.

12 Castro MJ, Apple DF, Hillegass EA, Dudley GA. Influence of complete spinal cord injury on skeletal muscle cross-sectional area within the first 6 months of injury. Eur J Appl Physiol Occup Physiol 1999; 80: 373-378.

13 Flanders A, Schaefer D, Doan H, Mishkin M, Gonzalez C, Northrup B. Acute cervical spine trauma: correlation of MR imaging findings with degree of neurologic deficit. Radiology 1990; 177: 25-33.

14 Flanders A, Spettell C, Tartaglino L, Friedman D, Herbison G. Forecasting motor recovery after cervical spinal cord injury: value of MR imaging. Radiology 1996; 201: 649-655.

15 Boldin C, Raith J, Fankhauser F, Haunschmid C, Schwantzer G, Schweighofer F. Predicting neurologic recovery in cervical spinal cord injury with postoperative MR imaging. Spine 2006; 31: 554-559.

16 Lundell H, Barthelemy D, Skimminge A, Dyrby TB, Biering-Sørensen F, Nielsen JB. Independent spinal cord atrophy measures correlate to motor and sensory deficits in individuals with spinal cord injury. Spinal Cord 2011; 49: 70-75.

17 Bozzo A, Marcoux J, Radhakrishna M, Pelletier J, Goulet B. The role of magnetic resonance imaging in the management of acute spinal cord injury. J Neurotrauma 2011; 28: 1401-1411.

18 Burns AS, Marino RJ, Flanders AE, Flett H. Clinical Diagnosis and Prognosis Following Spinal Cord Injury Vol 109 1st edn. Elsevier B.V. (2012).

19 Wilson JR, Grossman RG, Frankowski RF, Kiss A, Davis AM, Kulkarni AV et al. A clinical prediction model for long-term functional outcome after traumatic spinal cord injury based on acute clinical and imaging factors. J Neurotrauma 2012; 29: 2263-2271.

20 Ellingson BM, Salamon N, Holly LT. Imaging techniques in spinal cord injury. World Neurosurg 2014; 82: 1351-1358.

21 Scivoletto G, Tamburella F, Laurenza L, Torre M, Molinari M. Who is going to walk? A review of the factors influencing walking recovery after spinal cord injury. Front Hum Neurosci 2014; 8: 141.

22 Miyanji F, Furlan J, Aarabi B, Arnold P, Fehlings M. Acute cervical traumatic spinal cord injury: MR imaging findings correlated with neurologic outcome-prospective student with 100 consecutive patients. Radiology 2007; 243: 820-827.

23 Flanders A, Spettell C, Friedman D, Marino RJ, Herbison G. The relationship between the functional abilities of patients with cervical spinal cord injury and the severity of damage revealed by MR imaging. AJNR Am J Neuroradiol 1999; 20: 926-934.
24 Ramón S, Domínguez R, Ramírez L, Paraira M, Olona M, Castelló T et al. Clinical and magnetic resonance imaging correlation in acute spinal cord injury. Spinal Cord 1997; 35: 664-673.

25 Martin AR, Aleksanderek I, Cohen-Adad J Translating state-of-the-art spinal cord MRI techniques to clinical use: A systematic review of clinical studies utilizing DTI, MT, MWF, MRS, and fMRI. Neuroimage Clin 2016; 10: 192-238.

26 Dietz V, Colombo G, Jensen L. Locomotor activity in spinal man. Lancet (London, England) 1994; 344: 1260-1263.

27 Scivoletto G, Tamburella F, Laurenza L, Foti C, Ditunno JF, Molinari M. Validity and reliability of the 10-m walk test and the 6-min walk test in spinal cord injury patients. Spinal Cord 2011; 49: 736-740.

28 van Hedel HJ, Wirz M, Dietz V. Assessing walking ability in subjects with spinal cord injury: validity and reliability of 3 walking tests. Arch Phys Med Rehabil 2005; 86: 190-196.

29 Saraf P, Rafferty MR, Moore JL, Kahn JH, Hendron K, Leech K et al. Daily stepping in individuals with motor incomplete spinal cord injury. Phys Ther 2010; 90: 224-235.

30 Tudor-Locke C, Burkett L, Reis JP, Ainsworth BE, Macera CA, Wilson DK. How many days of pedometer monitoring predict weekly physical activity in adults? Prev Med (Baltim) 2005; 40: 293-298.

31 Ditunno JF, Ditunno PL, Graziani V, Scivoletto G, Bernardi M, Castellano V et al. Walking index for spinal cord injury (WISCl): an international multicenter validity and reliability study. Spinal Cord 2000; 38: 234-243.

32 Gandevia SC. Spinal and supraspinal factors in human muscle fatigue. Physiol Rev 2001; 81: 1725-1789.

33 Smith AC, Parrish TB, Abbott R, Hoggarth MA, Mendoza K, Chen YF et al. Muscle-fat MRI: 1.5 tesla and 3.0 tesla versus histology. Muscle Nerve 2014; 50: 170-176.

34 Smith AC, Parrish TB, Hoggarth MA, McPherson JG, Tysseling VM, Wasielewski M et al. Potential associations between chronic whiplash and incomplete spinal cord injury. Spinal Cord Ser Cases 2015; 2: 15024.

35 Elliott JM, Pedler AR, Jull GA, Van Wyk L, Galloway GG, O'Leary SP. Differential changes in muscle composition exist in traumatic and nontraumatic neck pain. Spine (Phila Pa 1976) 2014; 39: 39-47.

36 Hu R, Zhou J, Luo C, Lin J, Wang X, Li X et al. Glial scar and neuroregeneration: histological, functional, and magnetic resonance imaging analysis in chronic spinal cord injury. J Neurosurg Spine 2010; 13: 169-180.

37 Magu S, Singh D, Yadav RK, Bala M. Evaluation of Traumatic Spine by Magnetic Resonance Imaging and Correlation with Neurological Recovery. Asian Spine J 2015; 9: 748-756.

38 Andreoli C, Colaiacomo MC, Rojas Beccaglia M, Di Biasi C, Casciani E, Gualdi G. $\mathrm{MRI}$ in the acute phase of spinal cord traumatic lesions: relationship between MRI findings and neurological outcome. Radiol Med 110: 636-645.

39 Chang Y, Jung T-D, Yoo DS, Hyun JK. Diffusion tensor imaging and fiber tractography of patients with cervical spinal cord injury. J Neurotrauma 2010; 27: 2033-2040.

40 Joshi SK, Liu X, Samagh SP, Lovett DH, Bodine SC, Kim HT et al. mTOR regulates fatty infiltration through SREBP-1 and PPAR $\gamma$ after a combined massive rotator cuff tear and suprascapular nerve injury in rats. J Orthop Res 2013; 31: 724-730.

41 Dulor JP, Cambon B, Vigneron P, Reyne Y, Nouguès J, Casteilla L et al. Expression of specific white adipose tissue genes in denervation-induced skeletal muscle fatty degeneration. FEBS Lett 1998; 439: 89-92.

42 Hodges $P$, Holm AK, Hansson T, Holm S. Rapid atrophy of the lumbar multifidus follows experimental disc or nerve root injury. Spine 2006; 31: 2926-2933.

43 Marcus RL, Addison O, Kidde JP, Dibble LE, Lastayo PC. Skeletal muscle fat infiltration: impact of age, inactivity, and exercise. J Nutr Health Aging 2010; 14: 362-366.

44 Goodpaster BH, Krishnaswami S, Harris TB, Katsiaras A, Kritchevsky SB, Simonsick EM et al. Obesity, regional body fat distribution, and the metabolic syndrome in older men and women. Arch Intern Med 2005; 165: 777-783.

45 Hilton TN, Tuttle LJ, Bohnert KL, Mueller MJ, Sinacore DR. Excessive adipose tissue infiltration in skeletal muscle in individuals with obesity, diabetes mellitus, and peripheral neuropathy: association with performance and function. Phys Ther 2008; 88 : 1336-1344. 